\title{
Methodology for Bathymetric Mapping Using Open-Source Software
}

\author{
Jānis DUMPIS ${ }^{1 *}$, Ainis LAGZDIN̦Š² \\ ${ }^{1,2}$ Latvia University of Life Sciences and Technologies, Lielā iela 2, Jelgava, LV-3001, Latvia \\ ${ }^{2}$ Institute of Food Safety, Animal Health and Environment 'BIOR', Riga, Latvia
}

\begin{abstract}
The modern technologies not only provide an opportunity to collect water depth data much more efficiently than in the past, but also there is a wide range of opportunities to process these data to develop bathymetric maps and perform various calculations in the computer environment. This research aims to construct a high-resolution bathymetric map by using open-source software. Lake Zebrus was selected as the study site, where fieldwork was performed to obtain the depth data and subsequently process to find optimal methodology for creating a bathymetric map. The methodology used in this research is modifiable for different purposes and is based on obtaining the best results from using open-source resources and knowledge of cartography. Lake Zebrus is an example how to perform accurate and state of the art bathymetric survey in a short time period. The area of Lake Zebrus is $\mathbf{4 1 7 . 5 7}$ ha. The lake has a small crooked coastline. Lake Zebrus has a maximum depth of $4.45 \mathrm{~m}$ and an average depth of $1.48 \mathrm{~m}$. Results from the bathymetric survey can be used for further research based on depth data. The research tasks are accomplished as the methodology selected is repeatable in the other lakes. The research results prove that this methodology can be used for a bathymetric survey and it is possible to obtain high-definition results using open-source resources.
\end{abstract}

Keywords - Bathymetric survey; echo sounder; lake; Lowrance; methodology; QGIS

\begin{tabular}{|lll|}
\hline \multicolumn{2}{l}{ Nomenclature } & - \\
GIS & Geographic information system & - \\
GPS & Global positioning system & - \\
Shp & Shapefile. Geospatial vector data format GIS software & - \\
\hline
\end{tabular}

\section{INTRODUCTION}

Bathymetric mapping provides results on a waterbody dimensions [1]. Bathymetry is the science of measuring and displaying the depth of water bodies [2]. Bathymetric maps are widely used to study the waterbed by determining the exact shoreline of the waterbody based on the former water level at the time of the depth measurements. It is of note that any lake's water level fluctuations are caused by processes such as atmospheric circulation, changes in solar radiation, which determine the thermal and ice regime of the lake, as well as precipitation [3]. Using a bathymetric map it is possible to determine the morphometry of a waterbody, which can be used to correctly classify a waterbody. The classification of the

* Corresponding author.

E-mail address: janisdumpis94@gmail.com 
lakes is needed to understand their potential for use. From all the ecosystems, the lakes are one of the most sensitive to changes in the surrounding area thus hydrometry studies at any waterbody deserves a special attention [4]. The lakes contain a significant amount of the world's freshwater reserves so it is important to take care of their water quality. Water quality in the lakes influences the quality of drinking water, recreation, and fishing in the area [5]. The lakes are an important component of the ecosystem [6]. A small number of European lakes morphometry are regularly monitored [5]. In the world, the study of the lakes in terms of physical, chemical and biological characteristics has been developing rapidly since the beginning of the $20^{\text {th }}$ century [7]. The lakes are sensitive to climate change [8]. In Latvia, bathymetric surveys do not occur often enough as a result the changes in water bodies are not assessed and noticed on a regular basis.

The bathymetric map of the lake shows the distribution of the water depth of the lake, its variability and the terrain. Water depths are important in several physical and biological processes that occur in the lake. The depth of the lake influences its water quality, economic exploitation potential (fishing, recreation, shipping, water abstraction for agricultural use, drinking) [7]. The bathymetric map of the lake varies according to natural conditions, terrain and human economic activity.

A bathymetric map constructed from high-resolution depth data is required to conduct bathymetry research. Bathymetric mapping is the process by which depth maps are created based on the data collected [2]. Nowadays, data is obtained with echo sounders. The echo sounder is a device that can determine the depth of a body of water, underwater terrain, deciphering sunken objects. Analyzing bathymetry studies around the world, it can be concluded that costly technologies, rarely available to anyone, are used to construct maps [14].

This study was initiated in 2015 when field measurements presented in this study were done. This was a first attempt to construct a bathymetric map using self-collected data. On early stage of this study a lot of problems with data interpretation, interpolations, isobaths construction, data classification were faced. After practicing on differential data and using multiple computer programs this study was concluded in 2020 when acceptable open-source bathymetric map constructing methodology was elaborated. The methodology contains only open source data processing tools. In Latvia, there is exceptional coverage with open source data and it is possible to create high definition maps using only open source capability. Highquality mapping has a wide range of applications. The study shows how to draw/construct bathymetric maps, how to collect and interpret data. The results prove that high-quality state of the art research can be performed using open-source data processing tools. The study is designed to be completed within three workdays. On the first day, preparatory work including preparation of inventory and software, construction of the shoreline was carried out. The second day involves data collection and quality control. On the third day, the data processing, conversion, interpolation, construction of the bathymetric map, preparation of the results for potential further research were carried out.

Lake Zebrus was chosen as the object of this research. Lake Zebrus is located in the middle part of Latvia in the Lielauce Hills of the Eastern Kurzeme, $86.5 \mathrm{~m}$ above sea level [10]. Lake Zebrus is part of a complex nature reserve Zebrus and Svete with its surrounding landscape [10]. The nature reserve was established in 1957 and covers a total area of 928 ha. The reserve includes Zebrus and Svete lake, swampy depressions to the northwest and southeast of Lake Zebrus, and the lowland between the two lakes [9]. Lakes Zebrus and Svete have formed in a wide hilly valley. The two lakes are separated by a $500 \mathrm{~m}$ wide lowland (Svete mire), in the past, the lakes have been merged [10]. The Lake Zebrus is of glacial origin as a result of 
glacial activity. The lake has an oval shape. According to the literature the area of the lake is 482 ha, which suggests that Lake Zebrus is of medium size (250-500 ha) [11]. After fieldwork and processing of the results, it was determined that the area of the lake is 417.57 ha. The lake has a small passage, which is provided by a small river of Zusupite flowing northwest and the inlet channel from Lake Svete. The Zusupite is turned into a drainage ditch, which flows into the Svete River and furthermore in the Lielupe River. These places cannot be found in nature, because the shores of the lake are overgrown, therefore, neither the inlet channel nor the Zusupite can easily be found in the nature.

The study summarizes historical information on bathymetry mapping in Latvia and availability of bathymetric maps today. Currently, bathymetric maps that are publicly available in Latvia are only available in an image format. The maps are based on the measurement data obtained during the first independence of Latvia and years of the Soviet Union, which are outdated and inaccurate today as more than 80 years have passed and waterbodies have changed since then.

In Latvia depth measurements in $20^{\text {th }}$ century were made using lath or a weight tied at the end of a string [12]. In other European countries in the bathymetric research since $20^{\text {th }}$ century beginning echo sounder is used for depth measurement [1]. Data processing is mainly done using GIS tools with data interpolation and interpretation [13]. Measuring data with an echo sounder allows measurements to be taken every meter and even more frequently. The lake is carefully surveyed to ensure that important subtleties of the lake bed are not missed. Such data acquisition is incomparably faster it is possible to survey large bodies of water. All work from data collection to the finished bathymetric map can be done by one or a few people, does not take long time and can be processed in one day.

Morphometry studies require regular bathymetric surveying of the waterbody, which can detect changes [13] and identify their causes. Bathymetry studies are important to analyze the waterbody (morphometry), its light conditions, temperature distribution, amount of oxygen dissolved in water, and functionality of various depth ranges [14]. It is important to know the depth of the body of water as it can explain the physical and biological processes in the body of water, determine the possible light regime in the body, which in turn allows describing what is most likely to grow in the body [14].

The purpose of this study is to prove that a high-resolution bathymetric map can be constructed using freely available software.

The following tasks have been set:

- to develop a methodology suitable for a depth map construction using open-source tools;

- to test and calibrate the methodology by performing bathymetric mapping on Lake Zebrus;

- summarize the results of the study by describing potential risks, shortcomings, and improvements in the methodology.

\section{Methodology}

The computer programs that are used in during this research are MapCreator, QGIS, GRASS $G I S$, which are a free-access mapping software. When starting work on the construction of bathymetric maps it was important to know what methodology was used to construct publicly available maps. The developement process of the methodology was challenging due to the limited information available. The methodology only includes free data processing tools. 
Such a methodology is needed so that bathymetric studies can be conducted by anyone with appropriate knowledge, but without financial investements. Such studies provide an opportunity to popularize and improve bathymetric mapping.

The bathymetric mapping must adhere to basic principles for which cartographer or GIS experts can look for their solutions.

The basic principles are as follows:

- Card base with known recording time - required for the construction of the shoreline, water level calculation;

- Data collection and inventory - equipped boat;

- Data conversion tool for the research design demanding data format;

- Cartographic tool for processing, editing, calibration of acquired vector data, computer program;

- Results processing, map construction, interpolation and extrapolation, result creation tool, a computer program.

\subsection{Planning and Fieldwork}

The bathymetric survey presented in this study was carried out in Lake Zebrus. As part of the fieldwork, an expedition to Lake Zebrus was organized on December 3, 2015 to survey the lake and obtain depth measurement data. The bathymetric study was carried out by marking the coastline using the free map server of the Latvian State Forest. The research of bibliographic data concluded that the lake was last qualitatively mapped in 1932/1933 [12]. The latest bathymetric maps available on several websites are identical to 1932/1933. The inventory necessary for the research has been prepared. It is necessary to determine an altitude by a certain point followed by leveling accurately at 3 locations on the lake. Based of the data obtained an average altitude for Lake Zebrus was calculated.

Lake Zebrus was surveyed using a modern technology powered Sketter 190 SL motorboat with a $150 \mathrm{hp}$ Yamaha engine. The boat's echo sounder transducer was placed $25 \mathrm{~cm}$ below the water level, therefore, $25 \mathrm{~cm}$ were added to all data when processing it. The results of the study will be reflected on a bathymetric map with a resolution of $50 \mathrm{~cm}$. The bathymetric map of this resolution is more easily perceived by the user. Shorter intervals between isobaths provide a more detailed representation of the bathymetry of the waterbody [14], which in turn yields more accurate results in morphometric studies. The higher degree of detail in bathymetric map is used, the more accurate the morphometric parameters can be calculated. The lake depth measurement data were obtained with the Lowrance Elite 5 CHIRP echo sounder. The echo sounder transducer adjustment is a critical point for results accuracy. It is important to adjust the echo sounder correctly to minimize the risk of error and reduce data editing. It is necessary to connect the echo sounder to a high-resolution GPS. When recording data the most accurate depth data can be obtained at a frequency of $200 \mathrm{kHz}$. Higher frequencies can be used to search for specific subjects, but for recording depth data the best results can be achieved using $200 \mathrm{kHz}$. The recording is done in normal Primary and DownScan modes.

It is more convenient to carry out surveys in spring or autumn when there are no vacationers, anglers in the waterbody that would interfere with the survey of the lake or who could be disturbed by the survey. The depth measurements of Lake Zebrus were made after the end of the active water tourism season with a total of 746705 measurements (Primary and DownScan combined) within 5 hours, which is approximately 71 measurement point per $\mathrm{m}^{2}$. If the waterbody to be surveyed had a more complex bed structure, more measuring points 
would be required. The next step is to extract raw material data. Both Lowrance and Humminbird echo can be used for data recording. In this study, we were looking at data capture with Lowrance hardware. The survey was conducted with the boat moving at a steady speed in a circular motion along the lake. The recommended speed for recording data is $25 \mathrm{~km} / \mathrm{h}$ including avoiding sharp turns, stopping and starting. Important is to keep up with data recording for maximum precision for data records [15].

Primary sonar is intended to more accurately determine depth, identify objects in the bed, and understand the terrain. The DownScan Sonar is also designed to accurately determine depths and identify objects on the bed. This function is important for the machine to accurately determine where objects are located. Different noise are caused by smaller or larger sunken objects andfish. These sonar data can be combined using the overlay mode in the echo cancellation to provide a clear ground image, but more so when searching for specific objects.

When recording data it is suggested not to record for more than two hours to improve data security. There are two benefits of doing this, if the data is incorrect in one of the records and the record has to be repeated without losing all-day work and processing and editing at the same time resources, resulting in high-performance computing that does not require research. It is important to check the quality of the data after the research done on the body of water to meet the objectives stated.

A comparison of research methods with previous research methods has led to significant technological advances. Lake Zebrus was first mapped using an echo sounder as a depth measuring instrument. In previous studies the data were obtained by drilling ice during the winter icecap period of the lake and measuring the depth at the specific measurement site using a lote (shallow spot) and a weight-cords (deeper). It required a great deal of time, the involvement of several people, and special equipment as fieldwork took place in the winter. This kind of measurement data may not be accurate for nowadays standards asmore precise and accurate technologies are available now. The results of measurementswere not easily transferable because it was written down and could be destroyed in the event of an accident or mistake resulting in the loss of a large amount of research. The most important disadvantage of manual data measurements is the time consumed, manpower required and accuracy of the result. It is not known how the ice thickness was included in the results since it is also water but in a solid form. Knowing that water has a higher density than liquid, it was difficult to calculate the value to assign to the thickness of the ice. The depths of the waterbody were measured from the ice surface to the lake bed, which ultimately results in inaccuracies. Measuring in the ice-free period would be difficult in the deepest parts of the body of water because of the disturbance of the wind. To accurately measure the depth, a heavy anchor would be required and the boat should be anchored so that the line to be measured would not bend and cause inaccuracies [12].

\subsection{Bathymetric Map Construction Methodology}

After successful fieldwork and first-time data quality control further data handling requires in-depth quality control of the depth data. It is necessary to make sure that the depth measurements are correctly located on the bottom of the waterbody. The location control can be performed with the ReefMaster sonar viewer. The quality contral at this stage consists of deleting the location controls and error points, After converting the data into MapCreator software it is necessary to set up shp file geometry, coordinate system, and projection. This action can be performed in QGIS. The research was carried out in the Latvian geodetic coordinate system LKS-92. The next step is to correct the location of the data according to the position of the GPS receiver in the boat. This action is required if the GPS is not located 
directly at the echo-position. In the study, the GPS was located directly at the echo sounder transducer and no correction were required. It should be taken into consideration that this type of adjustment may present additional risks for unnecessary errors. The study data were collected in one day, which makes data processing compact and possible to done in approximately one working day. If data is collected for several days, it is necessary to reconcile them at the same water level, and this operation can lead to significant errors. It is desirable to do the job sequentially day after day without skipping for a long time. It will also be difficult and challenging to reconcile the data if obtained with a different boat. This type of research can take several days in field work need experience in bathymetric surveys and is not recommended in first-time research.

One of the most important steps is data interpolation. In the study interpolation was performed using GRASS GIS software. The interpolation method used involves the conversion of data into a raster file using the Bicubic interpolation method. In this way it is possible to obtain the most accurate results that represent the waterbed. It should be remembered that this method can take several hours to interpolate depending on the performance of the computer and size of the mapped area, If it is necessary the dataset can be spited into several parts and after interpolation merged. This procedure can lead to errors because it is necessary to overloop raster files to avoid errors in raster file sides. The raster needs to be constructed with the smallest possible pixel sizeunderstanding the data quality and selecting the most appropriate pixel size. It is advisable to construct several patterns with different pixel sizes, compare them and choose the most accurate and appropriate one. Successful data interpolation requires constructing isobaths. Both QGIS and GRASS GIS can be used to construct isobaths from the raster image created to avoid the possibility of errors. Isobath and raster Constructing and verifying is done until the desired result and accuracy is achieved. After successful construction of the isobaths using QGIS or GRASS GIS tools, a depth region shp file is constructed for high-quality visualization of the data.

The obtained results are systematically saved for further use, bathymetric map construction, shoreline verification. The results obtained are formatted for conversion to at 5 format for use in echo, conversion to KML file for mobile use, image conversion, GeoTIFF, Layer, underwater terrain model conversion. The results achieved can be used for a wide range of applications and functionality.

\section{RESUlTS AND DISCUSSION}

The computer programs used in this study can be replaced by other open-source programmes with similar functions. The research includes preparation for fieldwork, fieldwork, data logging, data export, conversion, editing, interpretation, interpolation, extrapolation, presentation, conversion for further detailed studies.

The obtained research results allow a qualitative description and analysis of Lake Zebrus. Using the bathymetric map it is possible to determine the lake dimensions, area, maximum depth, coastline length, latitude, longitude, calculate volume, and average depth. Lake Zebrus morphometry calculations and bathymetric maps were prepared at the water level of $87.44 \mathrm{~m}$ above the sea level, which were assumed as a zero point.

Based on the results of the fieldwork, a high-resolution bathymetric map with isobaths every 0.5 meters in depth was successfully constructed (Fig. 1). The bathymetric map is detailed enough to reflect the slightest change in depth in the lake. The estimated area of Lake Zebrus is 417.57 ha. The lake has a small crooked coastline. Lake Zebrus has a maximum depth of $4.45 \mathrm{~m}$ and an average depth of $1.48 \mathrm{~m}$. 


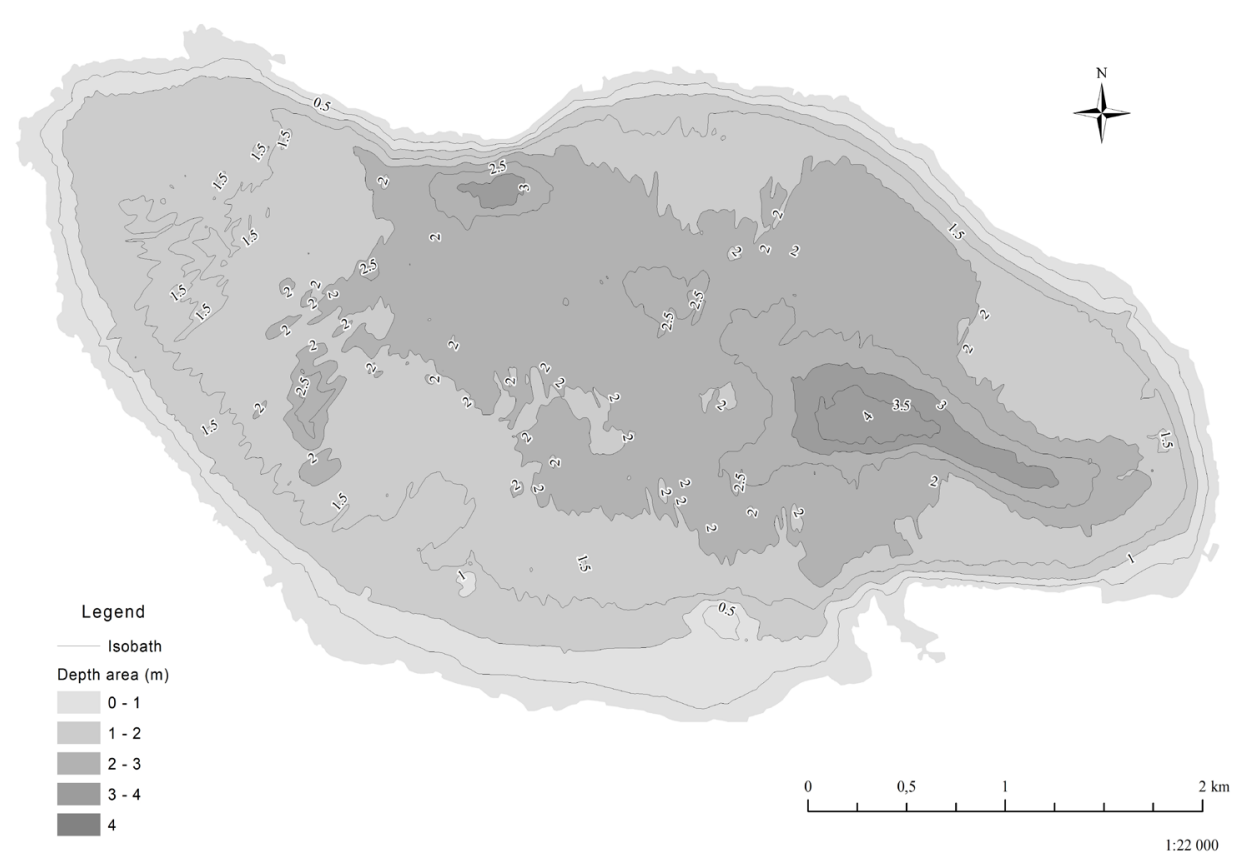

Fig. 1. Lake Zebrus bathymetric map.

The analytical bathymetric map (Table 1) shows that $81.8 \%$ of the lake area is deeper than $1 \mathrm{~m}, 35.32 \%$ is deeper than $2 \mathrm{~m}, 2.49 \%$ is deeper than $3 \mathrm{~m}$, but only $0.014 \%$ or $590 \mathrm{~m}^{2}$ is deeper than $4 \mathrm{~m}$. The value is understood as the distribution of the waterbody by depth layers, $81.8 \%$ of the lake is at least 1 to $2 \mathrm{~m}$ deep, $35.32 \%$ of the lake is at least 2 to $3 \mathrm{~m}$ deep. $81.8 \%$ of the lake area is deeper than $1 \mathrm{~m}, 35.32 \%$ is deeper than $2 \mathrm{~m}, 2.49 \%$ deeper than $3 \mathrm{~m}$, but only $0.014 \%$ or $590 \mathrm{~m}^{2}$ is deeper than $4 \mathrm{~m}$. The value is understood as the distribution of the waterbody by depth layers, $81.8 \%$ of the lake is at least 1 to $2 \mathrm{~m}$ deep, $35.32 \%$ of the lake is at least 2 to $3 \mathrm{~m}$ deep. The specific area occupied by each depth interval is indicated in the column labeled area between two isobaths. The longest of the isobaths is $2 \mathrm{~m}$ deep. Lake Zebrus has five depths areas, the largest area is 1-2 $\mathrm{m}$ deep, 194.1 ha of the total area of the lake, which is 417.57 ha. The largest part of the volume of Lake Zebrus is occupied by a depth of 2-3 m, totaling 299 million $\mathrm{m}^{3}$, or $48.36 \%$ of the total volume, which is $6182990.7 \mathrm{~m}^{3}$. The table is used to accurately describe and characterize the depth of Lake Zebrus, its area and volume. Using data on the area occupied by each depth level, one could infer the potential overgrowth of the lake and conclude the water temperature in the lake at various depths.

The methodology used in the study is modifiable and changeable. It is possible to use different echo sounder for depth measurements, the importance of the echo sounder accuracy, the ability to connect it to GPS, the ability to use recorded data. Five years of experience in the construction of bathymetric proves Lowrance echo sounder availability and functionality for bathymetric surveys. 
TABle 1. LaKe ZeBrus Bathymetric SurVey SumMary Results

\begin{tabular}{llllllll}
\hline Depth, $\mathbf{m}$ & $\begin{array}{l}\text { Area, } \\
\text { ha }\end{array}$ & $\mathbf{\%}$ & $\begin{array}{l}\text { Length of } \\
\text { isobaths, } \\
\mathbf{m}\end{array}$ & $\begin{array}{l}\text { Depth } \\
\text { area, } \mathbf{m}\end{array}$ & $\begin{array}{l}\text { The area } \\
\text { between two } \\
\text { isobaths, ha }\end{array}$ & $\begin{array}{l}\text { Volume, } \\
\mathbf{m}^{\mathbf{3}}\end{array}$ & $\mathbf{\%}$ \\
\hline 0 & 417.57 & 100 & 10410.90 & $0-1$ & 75.97 & 321515.52 & 5.20 \\
1 & 341.60 & 81.800 & 8541.80 & $1-2$ & 194.10 & 2553575.16 & 41.30 \\
2 & 147.50 & 35.320 & 11746.50 & $2-3$ & 137.12 & 2990403.45 & 48.37 \\
3 & 10.40 & 2.490 & 1873.20 & $3-4$ & 10.32 & 315332.53 & 5.10 \\
4 & 0.06 & 0.014 & 145.90 & $4-4.45$ & 0.06 & 2164.05 & 0.04 \\
\hline $\begin{array}{l}\text { Total number } \\
\text { of depth } \\
\text { measurements }\end{array}$ & 746705 & & & Sum & 417.57 & Sum & 6182990.70 \\
\hline $\begin{array}{l}\text { Number of } \\
\text { depth } \\
\text { measurements } \\
\text { per ha }\end{array}$ & 1788 & & & & & & \\
\hline
\end{tabular}

High-quality data conversion is possible on some Humminbird models and some Lowrance models. Quality results from Humminbird models can be achieved with the first and second generation Helix series. Lowrance hardware is recommended for Hook, Hook-2, first and second-generation HDS Carbon machines, first-generation Elite-TI machines. When recording data it is suggested to choose a recording format, which contains needed information for the study, For example, if there is a need to construct a bathymetric map to record data in a format that does not include water surface temperature and bed hardness, so we do not create unnecessary data. It is important to understand and choose the most appropriate method to directly survey the waterbody. Lake Zebrus is surveyed as the boat moves in a circular motion along the perimeter of the waterbody with each boat moving away from the shore, eventually circling the body of water several times from one to the other. Another method of surveying a waterbody is by measuring in the form of profiles [16]. This method is useful when recording echoes side-scan sonar data for submerged objects since side scan images are perceptible and usable when they are in a straight line so side views do not overlap. For data conversion, it is recommended to choose a conversion tool that does not simplify and generalize the results, but instead preserves the accuracy of the data. It is not recommended to round the depth measurement values as this will not allow the construction of high-resolution underwater terrain models. It is most convenient to convert the data immediately into shp format or XYZ file. Further processing and editing of data depend on the capabilities of each. Lowrance track files are easier to edit with ReefMaster SonarViewer, Humminbird track files are easier to edit with HumViewer. Editing is also possible using QGIS software, but it will not be possible to see the sonar screen and the depth point location relative to the waterbed at the same time making it harder to spot error areas. The errors can be caused by various environmental disturbances, boat speed, the magnetic field of large metal objects, which can cause GPS disturbance, fish bars, sunken objects, overgrowth.

Each next step in the study gives more options for methodology customization for desired results. Research results prove that data interpolation offers a wide range of cartography software applications. It is important to keep in mind that only Bicubic interpolation methods will produce quality results. Bicubic interpolation method give the accurate result in Lake Zebrus bathymetric survey. The choice of the interpolation method depends on the quality of the data. If the data is high resolution and we are not using precise enough interpolation 
methods like the Natural neighbor method we do not use the full potential of the data. After successful data interpolation, the most appropriate option for constructing the isobaths must be selected. The resulting isobaths show us the relief of the lake bed, so they must represent it in the highest quality possible. The higher the resolution of the isobaths the greater the focus on the accuracy of the interpolation results. The bathymetric mapping of Lake Zebrus was done in QGIS software. The design of bathymetric maps is very important, so it is recommended to choose a design tool with the widest range of options to present the research result.

Remote sensing methods are an alternative way of data collection as can be applied to larger water bodies. The use of remote sensing methods is more cost-effective as it does not require as much money and working hours to survey a body of water as it does to manually survey a body of water by boat [17]. In the case of Latvia, this research method is not an alternative because such data are not available. In Latvia, the only qualitative and economically feasible way to obtain data is by surveying a waterbody with an echo sounder. Additional alternative is to use drones for mapping water bodies. A drone will give the possibility to use time moreefficiently and surveyed larger areas.

By studying water bodies it is possible to carry out the qualitative characterization of the lake and monitor changes. By performing bathymetric studies it is possible to detect changes in water bodies promptly. By combining the results of bathymetric studies and other environmental monitoring studies can provide a high degree of detail in assessing the effects of climate change and anthropogenic impacts.

\section{Conclusions}

The methodology described and applied is suitable for bathymetric studies with high resolution and functionality results. The methodology used to construct a bathymetric map serves as guidelines for other bathymetric surveys methodology construction. The methods and software used during this study are interchangeable, which makes the methodology adjustable to needs of each user. The methodology is user-friendly because it allows you to create high-resolution bathymetric maps using open-source capabilities and different approaches.

\section{ACKNOWLEDGMENT}

This research has been supported by boat and fishing equipment company Eholotes.lv

\section{REFERENCES}

[1] Hakanson L. A Manual of Lake Morphometry. Springer, 1981. https://doi.org/10.1007/978-3-642-81563-8

[2] Jawak S. D., Luis A. J. Spectral information analysis for the semiautomatic derivation of shallow lake bathymetry using high-resolution multispectral imagery: A case study of Antarctic coastal oasis. Aquatic Procedia 2015:4:13311333. https://doi.org/10.1016/j.aqpro.2015.02.173

[3] Apsīte E., et al. Virszemes üdeñi. Latvija: zeme, daba, tauta, valsts (Surface water. Latvia: land, nature, nation, country). Rīga, LU Akadēmiskais apgāds, 273-330, 2018. (in Latvian)

[4] Agnieszka E. Ł., Adam C., Kurzyca I. Dynamics of Lake Morphometry and Bathymetry Various Hydrological Conditions. Polish Journal of Environmental Studies 2011:20(4):931-940.

[5] Perivolioti T. M., et al. Monitoring Water quality parameters of lake Koronia by means of long time-series multispectral satellite images. Auc Geographica 2017:52(2):176-188. https://doi.org/10.14712/23361980.2017.14 
[6] Schiefer E., Klinkenberg B. The distribution and morphometry of lakes and reservoirs in British Columbia: a provincial inventory. The Canadian Geographer 2004:48(3):345-355.

https://doi.org/10.1111/j.0008-3658.2004.00064.x

[7] Tundisi J. G., Matsumara-Tundisi T. Limnology. London: Taylor and Francis Group, 2012.

[8] Tan C., Ma M, Kuang H. Spatial-Temporal Characteristics and Climatic Responses of Water Level Fluctuations of Global Major Lakes from 2002 to 2010. Remote Sens. 2017:9:150:1-15. https://doi.org/10.3390/rs9020150

[9] Strautnieks I. Zebrus un Svētes ezers ar apkārtējo ainavu. Latvijas daba: enciklopēdija (Lake Zebrus and lake Svetes and their surrounding area. Nature of Latvia: encyclopedia). Rīga: Preses nams, 1998:6:18.

[10] Tidriḳis A. Zebrus ezers. Latvijas daba: enciklopēdija (Lake Zebrus. Nature of Latvia: encyclopedia). Rīga: Preses nams, 1998:6:17.

[11] Glazačeva L. Latvijas ezeri un ūdenskrātuves (Lakes and reservoirs of Latvia). Jelgava, LUA Institute of Water Management and Earth Science, 2004.

[12] Slaucītājs L. Morfometriskie elementi datiem Latvijas ezeriem. Geogrāfiskie raksti (Morphometric Elements for Data on Latvian Lakes. Geographical articles). Riga: Latvian Society of Geography, 1935:5:134-135.

[13] Hassen M. Y., et al. Bathymetric study of Lake Hayq, Ethiopia. Lakes and Reservoirs: Research and Management 2013:18(2):155-165. https://doi.org/10.1111//re.12024

[14] Gilberto F. B., Goncalves A. M., Garcia F. The Morphometry of Lake Palmas, a Deep Natural Lake in Brazil. Plos One 2014:9:11:1-14. https://doi.org/10.1371/journal.pone.0111469

[15] Boiten W. Hydrometry. The Netherlands: Taylor \& Francis, 2003.

[16] Sambuelli L., Bava S. Case study: A GPR survey on a morainic lake in northern Italy for bathymetry, water volume and sediment characterization. Journal of Applied Geophysics 2011:81:48-56. https://doi.org/10.1016/j.jappgeo.2011.09.016

[17] Yuzugullu O. Aksoy A. Generation of the bathymetry of a eutrophic shallow lake using WorldView-2 imagery. Journal of Hydroinformation 2014:16(1):50-58. https://doi.org/10.2166/hydro.2013.133 